\title{
The interplay between chromatin and transcription factor networks during B cell development: who pulls the trigger first?
}

\author{
Mohamed Amin Choukrallah ${ }^{1}$ and Patrick Matthias ${ }^{1,2 *}$ \\ 1 Friedrich Miescher Institute for Biomedical Research, Basel, Switzerland \\ 2 Faculty of Sciences, University of Basel, Basel, Switzerland
}

Edited by:

Ananda L. Roy, Tufts University School of Medicine, USA

\section{Reviewed by:}

Subbarao Bondada, University of Kentucky, USA

Kay L. Medina, Mayo Clinic, USA

Marcus R. Clark, The University of

Chicago, USA

*Correspondence:

Mohamed Amin Choukrallah and Patrick Matthias, Friedrich Miescher Institute for Biomedical Research, Maulbeerstrasse 66, Basel CH-4058, Switzerland

e-mail:mohamed-amin.choukrallah@ fmi.ch; patrick.matthias@fmi.ch
All mature blood cells derive from hematopoietic stem cells through gradual restriction of their cell fate potential and acquisition of specialized functions. Lineage specification and cell commitment require the establishment of specific transcriptional programs involving the activation of lineage-specific genes and the repression of lineage-inappropriate genes. This process requires the concerted action of transcription factors (TFs) and epigenetic modifying enzymes. Within the hematopoietic system, B lymphopoiesis is one of the most-studied differentiation programs. Loss of function studies allowed the identification of many TFs and epigenetic modifiers required for B cell development. The usage of systematic analytical techniques such as transcriptome determination, genome-wide mapping of TF binding and epigenetic modifications, and mass spectrometry analyses, allowed to gain a systemic description of the intricate networks that guide B cell development. However, the precise mechanisms governing the interaction between TFs and chromatin are still unclear. Generally, chromatin structure can be remodeled by some TFs but in turn can also regulate (i.e., prevent or promote) the binding of otherTFs. This conundrum leads to the crucial questions of who is on first, when, and how. We review here the current knowledge about TF networks and epigenetic regulation during hematopoiesis, with an emphasis on B cell development, and discuss in particular the current models about the interplay between chromatin and TFs.

Keywords: hematopoiesis, B cell development, transcription factors, chromatin regulators, pioneer transcription factors

\section{INTRODUCTION}

The character of a cell type is defined by its specific transcriptional program, which is regulated by transcription factors (TFs) that bind DNA cis-regulatory elements (cis-REs) to activate or repress defined set of genes. Cis-REs refer to loci that regulate the expression of genes located in the same molecule of DNA. They are composed of binding sites for TFs that recognize a specific nucleotide sequence and therefore act as trans-acting factors. Promoters and enhancers are the two major types of cis-REs in eukaryotes. At the DNA sequence level, the repertoire of cis-REs is identical in all cell types. Therefore, the transcriptional programs specific to each cell lineage must be the consequence of the repertoire of TFs expressed in a given cell that select genes for transcriptional activation or repression. However, the same TFs can be equally expressed in different cell types but have distinct binding profiles, indicating that the interaction between the TFs and their cognate sequences is not sufficient to explain the action of TFs and their transcriptional output. Indeed, in addition to the DNA sequence recognition, TFs occupancy strongly depends on chromatin structure and epigenetic modifications which provide an additional layer of gene regulation and establish heritable cellular memories.
Chromatin consists of repeating units of nucleosomes, comprising histone octamers (containing two copies each of $\mathrm{H} 2 \mathrm{~A}$, $\mathrm{H} 2 \mathrm{~B}, \mathrm{H} 3$, and $\mathrm{H} 4$ ) around which $147 \mathrm{bp}$ of DNA are wrapped (1). Multiple residues within the tails and the globular domains of histones can undergo post-translational modifications (PTMs), including acetylation, methylation, phosphorylation, ubiquitination, and sumoylation. These PTMs are catalyzed by a variety of histone-modifying enzymes that have been classified in two major groups, the writers such as histone acetyl transferases (HATs) and histone methyltransferases (HMTs) and the erasers such as histone deacetylases (HDACs) and histone demethylases (KDMs) (2) (Figure 1). Histone modifications act combinatorially to regulate transcriptional activity; some histone modifications are associated with transcriptional activation while others are associated with distinct mechanisms of transcriptional repression. For example, tri-methylation on lysine 4 of histone $\mathrm{H} 3$ (H3K4me3) is mainly associated with active promoters; in contrast, the mono methylation of the same residue ( $\mathrm{H} 3 \mathrm{~K} 4 \mathrm{mel})$ is a hallmark of poised and active enhancers, while H3K27ac marks exclusively active enhancers and promoters. The best studied repressive histone modifications are the methylation of lysines 9 and 27 of histone $\mathrm{H} 3$ (H3K9 and H3K27), which are respectively associated with 


\section{Condensed heterochromatin}
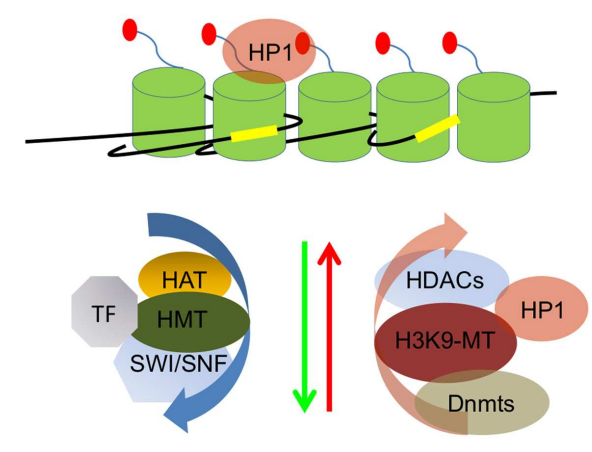

Active marks

H3K9me2/3

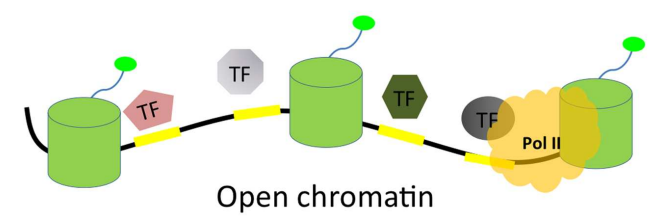

FIGURE 1 | Simplified scheme of condensed heterochromatin and open chromatin features. Heterochromatin is mostly hypo-acetylated, marked by methylated lysine 9 on histone $\mathrm{H} 3$ (H3K9me2/3) which forms a binding site for heterochromatin protein 1 (HP1), contains methylated DNA, and results from the action of repressive complexes such as histone deacetylases (HDACs), H3K9 methyltransferases (H3K9-MT), and DNA methyltransferases (Dnmts). Chromatin opening is orchestrated by the concerted action of transcription factors (TFs) and chromatin modifying enzymes such as histone methyltransferases (HMTs), histone acetyl transferases (HATs), and SWI/SNF remodeling complexes. Open chromatin is generally acetylated, harbors active histone marks, and is accessible to the transcription machinery and RNA polymerase II (Pol II). TF binding sites (TFBSs) are indicated by yellow rectangles and the nucleosomes consisting of histone octamers are depicted by green cylinders. For simplicity, only a single histone tail is shown protruding out of each nucleosome and DNA methylation is not depicted.

heterochromatin and polycomb-group (PcG) proteins-mediated repression.

DNA methylation provides yet an additional mechanism for gene regulation. It is an efficient repressive DNA modification that occurs at the fifth position of cytosine $(5-\mathrm{mC})$, mostly in the context of CpG dinucleotides (3) and is associated with transcriptional repression through two general mechanisms. First, DNA methylation can directly inhibit the binding of proteins important for transcription initiation, such as TFs and others. Moreover, methylated DNA can recruit proteins containing a methylated DBD, which may interfere with transcription by co-recruitment of repressors such as HDACs [reviewed in Ref. (4)]. Most of the genome is depleted of CpGs except for CpG islands, which represent ca. $60 \%$ of mammalian promoters and are largely unmethylated (5). DNA methylation is catalyzed by three enzymes: the maintenance DNA methyltransferase Dnmt1, which ensures that already methylated residues are faithfully maintained during DNA replication (6), and the de novo methyltransferases Dnmt3A and Dnmt3B which can add methyl groups to non-methylated CpG residues (7). DNA methylation is dynamic and also reversible: removal of methyl groups can occur through active or passive mechanisms. The latter is due to the absence of methylation by Dnmtl of newly synthesized DNA during replication. In contrast, active DNA demethylation corresponds to the reaction that leads to the removal of the methyl group from 5-mC residues independent of DNA replication. Active DNA demethylation has been a controversial subject as many mechanisms were proposed to explain this process and the putative demethylases could not be identified in a conclusive manner [reviewed in Ref. (8)]. However, it is now well accepted that the dioxygenases Tet 1 and Tet2 catalyze DNA demethylation through the conversion of 5-mC to hydroxymethyl cytosine $(5-\mathrm{hmC})(9,10)$.

Additional mechanisms involved in epigenetic regulation are contributed by chromatin remodeling complexes (CRC) and diverse kinds of non-coding RNAs. Chromatin remodelers are ATP-dependent complexes that regulate DNA accessibility by modifying nucleosome positioning and conformation. They can be divided into four groups: the SWI/SNF, ISWI, CHD, and INO80 families of remodelers [reviewed in Ref. $(11,12)$ ]. In addition, long or short non-coding RNAs can influence chromatin and gene expression, for example by mediating inactivation of one chromosome (X inactivation by Xist RNA), opening up loci or helping to define boundaries of chromatin domains [reviewed by Mercer et al. (13)].

These different mechanisms of histone modifications, DNA methylation, chromatin remodeling, and non-coding RNAs play a central role in shaping chromatin structure, which in turn affects the interaction between TFs and their cognate binding sites. Conversely, the binding of TFs triggers a chain of events, often leading to changes in local chromatin properties. Indeed, TFs can interact with and recruit many chromatin modifying or remodeling complexes to their target loci. Thus, establishing chromatin structure requires TF activity and TF activity depends on chromatin structure. This reciprocal interplay raises a major question: how is the communication between TFs and chromatin regulated and which additional cellular signals feed into this complex network during development and cellular differentiation?

Understanding the mutual and interdependent interactions between TFs and chromatin features and their impact on gene regulation in a developmental system requires a biological paradigm where successive differentiation stages can easily be identified and isolated. In this regard, hematopoiesis provides a powerful system to study epigenetic and transcriptional dynamics. B cells derive from hematopoietic stem cells (HSCs) through a multistep differentiation program. HSCs have both self-renewal and multipotency capacities. The precise balance of these properties is essential to maintain the HSC pool size throughout animal life. HSCs initially give rise to multipotent progenitors (MPPs) that loose self-renewal capacity but keep the ability to generate early progenitors of lymphoid and myeloid lineages. Lymphoid lineage consists of $\mathrm{B}, \mathrm{T}$, and natural killer (NK) cells while myeloid lineage contains macrophages $(\mathrm{M})$, granulocytes $(\mathrm{G})$, erythrocytes $(\mathrm{E})$, and megakaryocytes (Mk). The exact branching point between lymphoid and myeloid lineages as well as the differentiation potential of progenitor populations is still matter of some debate [reviewed in Ref. (14)]. The identification of common lymphoid progenitors (CLPs) (15) and common myeloid progenitors (CMPs) (16) supports the model that lymphoid and myeloid lineages follow 
distinct developmental paths from MPPs. This model was challenged by the identification of the lymphoid-primed multipotent progenitors (LMPPs) that loose MkE potential but keep lymphoid and GM potential $(17,18)$. Another study showed that the MPP compartment contains a subpopulation of cells with strong lymphoid potential and weak myeloid colony-forming activity (19). These cells, called early lymphoid progenitors (ELPs) start to express recombination-activating gene $1(\operatorname{Rag} 1)$ and Rag2 and initiate the immunoglobulin heavy chain $(\operatorname{IgH})$ rearrangement (19). ELPs are thought to precede the CLP stage. Recently, it was shown that the CLP compartment contains two distinct subpopulations: all lymphoid progenitors (ALPs) and B cell-biased lymphoid progenitors (BLPs) (20). ALPs retain full lymphoid potential, whereas BLPs behave essentially as B cell progenitors (20). Mature B cells derive from BLPs through sequential differentiation steps that can be defined by five major stages that are phenotypically and functionally distinct: pro-B, pre-BI, large and small pre-B II, and immature B cells (21) (Figure 2). Early B cell differentiation is intimately connected to the DNA rearrangement of Ig genes, the so-called $\mathrm{V}(\mathrm{D}) \mathrm{J}$ recombination, in order to generate functional Ig molecules. Pro-B cells, first express the pan-B cell marker B220 and this coincides with entry into the B cell lineage. Next, pre-BI cells express the CD19 gene and complete recombination of the IgH diversity $\left(\mathrm{D}_{\mathrm{H}}\right)$ to joining $\left(\mathrm{J}_{\mathrm{H}}\right)$ segments and the next stage sees the generation of $\operatorname{IgH} \mathrm{V}(\mathrm{D}) \mathrm{J}$ alleles [reviewed in Ref. (21)]. This allows expression of the rearranged heavy chain which assembles with the surrogate light chain to form the pre-B cell receptor (preBCR), a crucial checkpoint in B cell development (22). If cells pass this functional test they can go on to the next developmental stage, small pre-BII cells, where the Ig light chain rearranges and allows for the formation and exposure at the cell surface of a functional Ig molecule, the BCR. Finally, immature cells can then leave the bone marrow (BM) and enter the periphery (22).

The generation of immature and mature B cells from early precursors is a progressive process, every step of which is characterized by a specific transcription program involving the activation, repression, or maintenance of distinct sets of gene expression patterns. This genetic regulation results from the concerted action of ubiquitous and lineage-specific TFs as well as epigenetic modifiers. Proper and timely recombination of the Ig loci is essential for normal progression through B cell development and is highly dependent on chromatin structure, DNA methylation, and also expression of various RNAs across the Ig locus. In particular, the accessibility model, first posited by Frederick Alt and colleagues, highlighted the importance of "sterile" transcripts which originate from unrearranged Ig gene segments and make their chromatin accessible to the recombination enzymes RAG1 and RAG2 [reviewed in Ref. (23)]. Thus, B cell development presents an extraordinarily complex and dynamic system to study the establishment and maintenance of transcriptional and epigenetic networks.

\section{KEY TRANSCRIPTION FACTORS ESSENTIIAL FOR B CELL DEVELOPMENT}

Loss of function studies using mouse models have identified many TFs important for distinct stages during B cell development and a particular emphasis has been put on early B cell specification and commitment. Prominent among those are E2A, Ebf1, and Pax5, as well as other TFs acting downstream and upstream to these

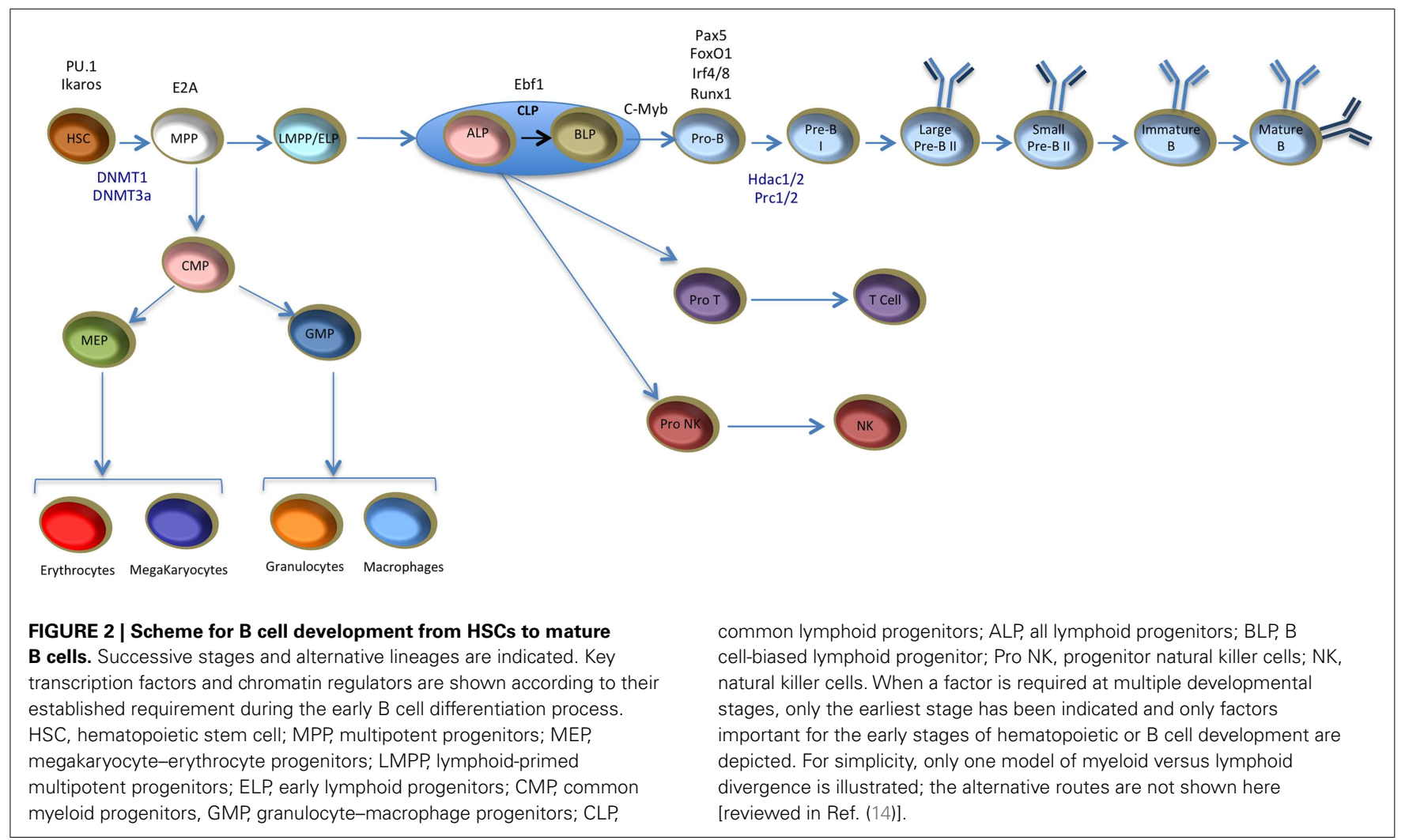


factors. Some of these TFs such as Ebf1 and Pax5 are restricted to the B cell lineage while others such as Ikaros, PU.1, E2A, and FoxOl are also involved in other lineage fate determination.

The expression of these TFs is temporally regulated; e.g., Ikaros, PU.1, and E2A are expressed in the very early progenitors including HSCs and MPPs before the commitment to the lymphoid branch, Ebf1 and FoxO1 are expressed at the CLP stage under the control of E2A (24) and Pax 5 expression is induced by the concerted action of Ebf1, FoxO1, and E2A in committed pro-B cells. The sequential expression and activity of these TFs suggests a hierarchy in their action. Yet, the transcriptional regulation of early B cell development is not a simple hierarchical cascade, as many of these TFs act in a cooperative manner and directly regulate the expression of other TFs, involving both positive and negative feedback loops leading to a complex cross-regulatory network (25) (Figure 3).

\section{PU.1}

If one considers a hierarchical classification of the TFs involved in B cell development, PU.1 and Ikaros come on the top of the regulatory pyramid. PU.1 (encoded by Spi-1, Sfpi-1) belongs to the ETS family of TFs, its expression was thought to be restricted to the hematopoietic lineage, but was recently also detected in adipocytes (26). Within the hematopoietic system, PU.1 activity is essential for the development of lymphoid cells as well as macrophages and neutrophils (27). Disruption of the PU.1 DBD in mouse prevents the commitment of MPPs toward the lymphoid lineage (27). PU.1 is expressed in HSCs (28), lymphoid, and myeloid progenitors (16) as well as in fully mature and functional cells (29). This broad expression pattern indicates that PU.1 is not only required for cell differentiation but also plays a role in the function of the specialized hematopoietic cells. The expression of PU.1 in many hematopoietic lineages raised the question about its mechanism of action and the rules that determine the interaction between this TF and its binding sites in different cellular and physiological contexts. Genome-wide mapping of PU.1 binding sites in macrophages and B cells revealed that PU.1 is enriched at transcription start sites (TSSs), but the majority of binding sites were found at inter- and intra-genic sites (30) indicating a role of PU.1 in regulating both transcription initiation and enhancer function. Interestingly, PU.1 binding at TSSs exhibits a high correlation between macrophages and B cells; in contrast, binding sites at distal regulatory elements are highly cell type-specific. Motif analysis of cell type-specific PU.1 binding sites revealed that PU.1 binds in vicinity of lineagespecific TFs: B cell-specific PU.1 binding sites are enriched in E2A, Ebf1, OCT, and NF-kB motifs, while macrophage-specific sites are enriched in C/EBP and AP-1 motifs (30). These findings strongly suggest that the cell type-specific function of PU.1 is partly due to its collaborative interaction with other lineage-specific TFs. The role of PU.1 in shaping the enhancer repertoire in hematopoietic cells will be further discussed in a later section of this review. Interestingly, PU.1 action was shown to depend critically on its expression level and involves a tight dose-dependent control. PU.1 shows low to medium expression level in LT-HSCs and exhibits varied levels in progenitors and mature cells; e.g., PU.1 is weakly expressed in erythroid and T cells and shows intermediate levels in B cells, in contrast, it is highly expressed in macrophages and neutrophils (31). Importantly, this graded expression has a critical

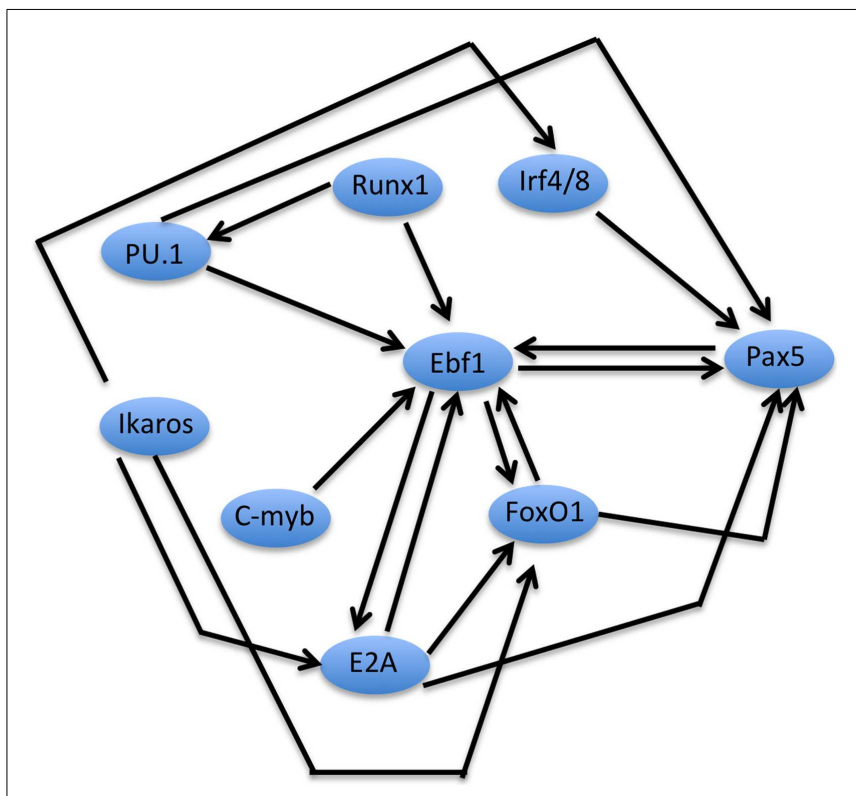

FIGURE 3 | An early B cell specification module. Schematized network of inter-dependent TFs regulating early $B$ cell development. The scheme depicts TFs that have been implicated in the control of early $B$ cell specification and/or commitment (for clarity, factors such as Spi-B, OBF1, or NF-KB, which are important at later stages of B cell development, are not depicted here). Direct positive regulation between two factors at the transcriptional level is indicated by the corresponding arrows. Note that the scheme does not imply biochemical interactions (e.g., complex formation) between the factors, although they may also take place in some cases.

role in specifying the different lineages: by artificial expression of PU.1 in PU.1-deficient progenitors, it could be demonstrated that moderate PU.1 levels promote B cell development, while high PU.1 expression promotes macrophage differentiation and at the same time blocks B cell development (32).

\section{IKAROS}

The zinc finger factor Ikaros (encoded by the izkf1 gene) also plays a critical role during early lymphoid lineage specification. Ikaros was proposed to promote the differentiation of pluripotent HSCs into the lymphocyte pathways: mutational disruption of the Ikaros DNA-binding domain (DBD) leads to an early block in lymphopoiesis before the commitment to the lymphoid restricted stages (33). However, another study showed that Ikaros is dispensable for the transition from HSCs to LMPPs, but is rather required for the progression of LMPPs into the lymphoid lineages (34). Recently, Ikaros was found to be required for the induction of lymphoid lineage priming in HSCs and for the repression of self-renewal and multipotency genes after HSC differentiation (35). Ikaros is also involved in later stages of B cell development, where it promotes heavy-chain gene rearrangements by inducing expression of the RAG1 and RAG2 genes, as well as by controlling accessibility of the variable gene segments and compaction of the IgH locus (36). Furthermore, Ikaros was recently shown to be required for the differentiation of large pre-B to small pre- $\mathrm{B}$ cells and for transcription and rearrangement of the IgL locus (37). Ikaros functions either as a transcriptional activator or repressor by 
recruiting various $\mathrm{CRC}$ including SWI/SNF and $\mathrm{Mi}$-2/nucleosome remodeling and deacetylase $(\mathrm{Mi}-2 / \mathrm{NuRD})$ to DNA regulatory elements and to pericentromeric heterochromatin (38-42).

\section{E2A}

E2A (encoded by $t c f 3$ with two splice variants, E12 and E47) is a helix-loop-helix TF essential for B cell differentiation $(43,44)$. E2A-null mutant mice fail to generate LMPPs and lack B cells (43). E2A acts synergistically with PU.1 and is required for Ebf1 and FoxO1 expression at the CLP stage $(45,46)$. Genome-wide mapping experiments in $\mathrm{B}$ cell progenitors (Ebf1 ${ }^{-/-}$and $\mathrm{Rag}^{-{ }^{-/}}$) showed that E2A binds both TSSs and putative enhancers (24) and is required to induce $\mathrm{H} 3 \mathrm{~K} 4 \mathrm{me} 1$ deposition at enhancer elements in concert with PU.1 (30).

\section{EARLY B CELL FACTOR 1}

Early B cell factor 1 (Ebf1) belongs to the EBF/COE family of TFs (47). EBF/COE family members contain an N-terminal DBD with an atypical zinc knuckle domain (H-X3-C-X2-C-X5-C), a TF immunoglobulin (TIG/IPT) domain, a helix-loop-helix-loophelix (HLHLH) domain and a carboxy-terminal transactivation domain (48). The HLHLH domain was found to be important for the dimerization of EBF1 (48). EBF1 is essential for B cell specification (49) and commitment (50). Ebfl acts in concert with E2A, FoxO1, and other TFs to regulate the expression of many genes required for $\mathrm{B}$ cell development including TFs such FoxO1 and Pax5 (51); the latter in turn binds to Ebf1 enhancers and increases its expression, thereby leading to a positive feedback loop between these two factors $(24,52,53)$. Ebf1 can also act as a repressor; indeed, it was shown that Ebf1 prevents Id2- and Id3mediated inhibition of the E47 isoform of E2A by downregulating the expression of their mRNA (54).

\section{Pax5}

Pax5 acts downstream of Ebf1, its expression is under the control of a cohort of TFs including PU.1, Ebf1, FoxO1, IRF4, and IRF8 (55). Pax5 is essential for B cell commitment (56) and maintenance of B cell identity through activation of B cell-specific genes and repression of lineage-inappropriate genes (57). Deletion of Pax5 in mature B cells leads to the de-differentiation to lymphoid progenitors, which can differentiate into functional $\mathrm{T}$ cells (58). The role of Pax5 in regulating gene expression will be discussed in more detail in a later section.

\section{Fox01}

The forkhead TF FoxO1 plays an important role during B cell development. FoxO1 was found to be critical at several stages of $\mathrm{B}$ cell differentiation (59). Early deletion of FoxO1 causes a substantial block at the pro-B cell stage due to a failure to express the IL-7 receptor-alpha chain. FoxO1 inactivation in late pro-B cells results in an arrest at the pre-B cell stage due to impaired expression of Rag1 and Rag2 (59), which are direct targets of FoxO1 (60). In addition, deletion of FoxO1 in peripheral $\mathrm{B}$ cells leads to reduced number of lymph node $B$ cells due to down regulation of L-selectin and defect in class-switch recombination (59).

\section{c-Myb AND Runx1}

$B$ cell development also depends on many other TFs such as for example c-Myb and Runx1. Deletion of c-Myb in mice leads to a block at the pre-pro-B cell stage which is accompanied with impaired expression of the alpha-chain of the IL-7 receptor and Ebf1 (61). Deletion of Runx1 also causes a developmental block at the pro-B cell stage accompanied by reduced expression of E2A, Ebf1, and Pax5. Furthermore, Runx1 directly binds the Ebf1 promoter and this binding is critical for Ebfl activation; indeed, Runx1-deficient pro-B cells were shown to harbor excessive amounts of the repressive histone mark H3K27me 3 in the Ebf1 proximal promoter. Interestingly, retroviral transduction of Ebf1, but not Pax5, into Runx1-deficient progenitors restores B cell development (62). It was also shown that Runx1 controls the expression of PU.1 via direct interaction with its upstream regulatory element (URE) (63).

As discussed above, many of the TFs critical for early B cell development directly regulate each other's expression, positively or negatively, by binding to cis-REs in their corresponding genes. This inter-dependent network forms a B specification module, which has EBF1 at its center, which in concert with Ikaros, E2A, IRF4/8, and FoxO1, positively activates expression of Pax5, thus locking B cell development (Figure 3).

\section{EPIGENETIC REGULATORS INVOLVED IN HEMATOPOIESIS AND B CELL DEVELOPMENT}

In addition to the TFs, many epigenetic regulators are crucial for hematopoiesis and/or B cell development. Among those, PcG proteins play an important role in this system. Mammalian cells contain two major PcG complexes, PRC1 and PRC2. PRC2 contains SUZ12, EED, and EZH1 or EZH2. EZH proteins are HMTs that catalyze the di- and tri-methylation of histone H3K27 (64). PRC1 contains RING1, CBX, PHC, and BMI1 or MEL18 [reviewed in Ref. (65)]. PRC1 recognizes and binds H3K27me3 via its subunit CBX, while RING1 mono-ubiquitylates histone H2A at lysine 119 (H2AK119ub1) (61, 62). The H2AK119ub1 mark is thought to play a role in inhibiting RNA polymerase II (pol II) elongation (66). The H3K27me3 mark is associated with the silencing of many key developmental regulatory genes, such as Hox homeotic genes and many others [reviewed in Ref. (67)].

Many PcG deficiencies correlate with defective development and/or activation of lymphocytes. For example, inactivation of Bmil or mel-18 causes a severe block in B cell development that leads to B cell lymphopenia $(68,69)$. By contrast, deficiency in Cbx2 does not affect lymphocyte development but alters splenic B cell response to lipopolysaccharide (LPS) (70). Conditional knockout studies targeting members of the polycomb machinery highlighted the critical role of these enzymatic complexes in the hematopoietic system. Bmil is the most studied PRC1 subunit in hematopoiesis. Depletion of Bmil leads to impaired self-renewal capacity of HSCs due to the de-repression of two major cell cycle regulators: Ink4a (p16) and Arf (p19) (71). Bmil directly binds and repress the promoters of these genes and the deletion of both Ink4a and Arf genes restores the self-renewal capacity of $\mathrm{Bmil}^{-1-}$ HSCs (72). Moreover, $\mathrm{Bmil}^{-1-}$ mice have a BM microenvironment that is severely defective in supporting hematopoiesis. In this case however, the deletion of both Ink4a and Arf genes did not significantly restore the impaired BM microenvironment (72). Bmil is also involved in the repression of Ebf1 and Pax5 in HSCs and MPPs. Depletion of Bmil causes aberrant expression of these two genes, leading to premature lymphoid lineage 
specification (73). Another PRC1 subunit, Ring1b, was also found to be critical for adult hematopoiesis. Mice deficient for Ring $1 \mathrm{~b}$ in hematopoietic cells develop a hypocellular BM that unexpectedly contains an enlarged, hyperproliferating compartment of immature cells, with an intact differentiation potential. These defects are associated with differential upregulation of cyclin D2 and Ink4a (74). Controlled expression of PRC2 components is also important for hematopoiesis. Several studies have highlighted the role of Ezh1 and Ezh2 in embryonic and adult HSCs. Loss of Ezh2 severely impairs fetal HSC self-renewal without affecting the function of adult stem cells present in the BM (75). In addition, EZH2 was also found to have a crucial role in early $\mathrm{B}$ cell development and in rearrangement of the IgH gene (66).

Early B cell development also requires HDACs activity (76). Targeted deletion of the major class I HDACs, HDAC1 and 2 showed that $\mathrm{B}$ cell development requires the presence of at least one of these two enzymes. When both enzymes are deleted, B cell development is dramatically impaired at the large pre-BII stage with a strong cell cycle block in the G1 phase accompanied by the induction of apoptosis. In contrast, elimination of HDAC1 and HDAC2 in mature resting B cells is not deleterious; however, when these cells are induced to proliferate cell cycle block and apoptosis ensue. These data indicate that the role of HDAC1 and 2 during early B cell development is at least partially linked to cell cycle control (76). The potential role of HDACs in controlling other processes in B cells and other hematopoietic lineages remains to be elucidated.

The activity of DNA methyltransferases is also crucial for hematopoiesis. Conditional deletion of the maintenance DNA methyltransferase Dnmt1 in HSCs leads to impaired self-renewal capacity and prevents HSCs from giving rise to hematopoietic progenitors (77). Based on the initial studies, loss of the de novo DNA methyltransferases, Dnmt3a or Dnmt3b alone was thought to have no impact on HSC function (78); by contrast, loss of both together was reported to abolish self-renewal without affecting differentiation capacity (78). However, a more recent study reported that Dnmt3a-null HSCs exhibit upregulation of multipotency genes and downregulation of differentiation factors. The progeny of Dnmt3a-deficient HSCs exhibit global hypomethylation and impaired repression of HSC-specific genes. These data highlighted the important role of Dnmt3a in the repression of HSC genes in order to enable proper cell differentiation (79).

$\mathrm{V}(\mathrm{D}) \mathrm{J}$ recombination of immunoglobulin genes is thought to be regulated by changes in the accessibility of target sites, such as modulation of methylation. In vitro experiments showed that specific methylation within the heptamer of recombination signal sequences markedly reduces $\mathrm{V}(\mathrm{D}) \mathrm{J}$ cleavage without inhibiting RAG1/RAG2-DNA complex formation (80). Recent investigations of the IgH locus recombination showed that the diversity $\left(\mathrm{D}_{\mathrm{H}}\right)$ and joining $\left(\mathrm{J}_{\mathrm{H}}\right)$ gene segments are methylated prior to recombination, in contrast the $\mathrm{DJ}_{\mathrm{H}}$ product is demethylated. $\mathrm{DJ}_{\mathrm{H}}$ junctional demethylation is restricted to B cells and requires the $\mathrm{E} \mu$ enhancer, located within the intronic region of the IgH locus (81). However, it is unclear whether the demethylation is required for $\mathrm{DJ}_{\mathrm{H}}$ junction or whether it is simply the consequence of the DNA recombination. Earlier experiments had shown that loss of methylation of the kappa light chain locus is not sufficient to activate recombination in cultured pre B cells lacking Dnmt1 (82). Cd19-cre mediated deletion of the de novo DNA methyltransferase Dnmt3a and Dnmt3b, failed to identify a critical role for these enzymes in B cell development (83). Cd19-cre is expected to induce the deletion of targeted genes from pre B cells onward (84). Thus, this study, strongly suggest that Dnmt3a and b are dispensable to the progression from pre B cells to mature B cells. Overall, these studies suggest that the maintenance DNA methyltransferase Dnmtl is required at all the stages of hematopoiesis, whereas the de novo DNA methyltransferases Dnmt3a and 3b are required only at the very early stages and become dispensable at later stages. However, additional studies will be needed to fully test these assumptions.

\section{INTERPLAY BETWEEN CHROMATIN LANDSCAPE AND TF ACTIVITY DURING B CELL DEVELOPMENT}

The progression of MPPs toward specialized cells is thought to be accompanied by extensive epigenetic reprograming. In the recent years, genome-wide technologies have been used to map histone modifications and TF binding sites (TFBSs) in various B cell populations and to describe the epigenetic changes accompanying $\mathrm{B}$ cell development. Recent studies in different systems indicated that the chromatin of cis-REs is in a pre-active state in stem cells and/or early progenitors before the transcriptional initiation, leading to the concept of "gene priming" (85). The priming is thought to be driven by a specific class of TFs called "pioneer TFs," that are able to induce the early chromatin changes during the gene activation process (86). Pioneer TFs are thought to mark certain loci for downstream activation during development. Cis-RE bookmarking by pioneer TFs was first described in the mouse liver where FoxA and Gata factors were found to bind the liver-specific enhancer of the alb1 gene in the precursor gut endoderm prior to its activation in nascent liver $(87,88)$. The appellation "pioneer TF" must meet the following criteria, although these have not always been unambiguously demonstrated in every case: (i) binding to the regulatory region prior to transcription activation, (ii) binding prior to the arrival of other factors, (iii) binding to their target sites in condensed chromatin, and (iv) being able to induce chromatin modifications and/or remodeling in order to render the locus accessible for downstream TFs [reviewed in Ref. (86)]. It is important to mention that in the majority of cases, it is difficult to establish unequivocally the exact binding chronology of a set of TFs at a given locus (see Figure 4).

Several studies have described primed enhancers (sometimes also called poised enhancers) in the hematopoietic system $(85,89)$. Primed enhancers refer to distal regulatory elements that harbor $\mathrm{H} 3 \mathrm{~K} 4 \mathrm{me} 1$ mark but lack acetylation marks such as $\mathrm{H} 3 \mathrm{~K} 27 \mathrm{ac}$ and $\mathrm{H} 3 \mathrm{~K} 9 \mathrm{ac}$; their associated genes are therefore not transcribed. In contrast, active enhancers harbor both $\mathrm{H} 3 \mathrm{~K} 4 \mathrm{me} 1$ mark and acetylation marks and their associated genes are transcribed. According to the current priming models, once a cell has reached terminal differentiation, its enhancer repertoire is completely established and maintained by cooperatively acting lineage-specific TFs. Inducible or regulated TFs that are activated by extracellular stimuli operate within this predetermined framework, landing close to where master regulators are already bound (Figure 5). However, this model was recently challenged by the identification of a novel class of 
A

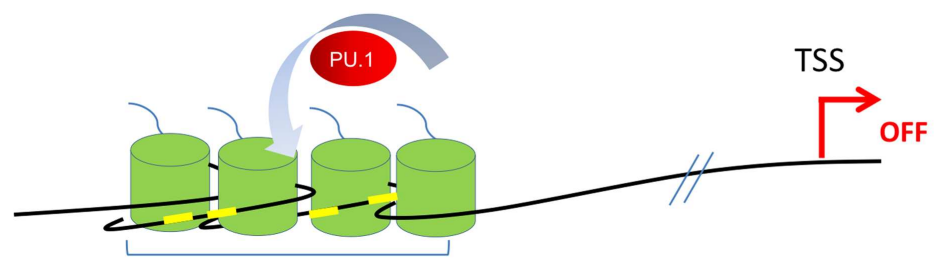

Enhancer

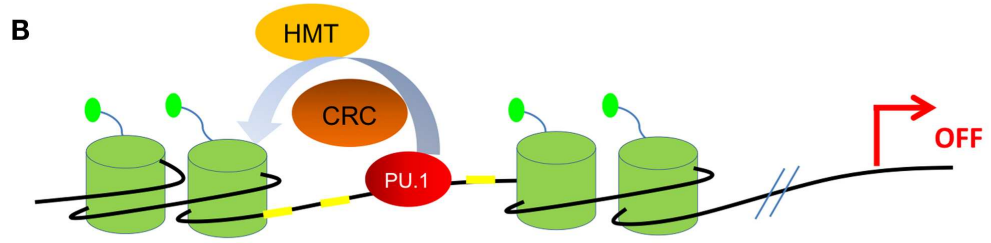

Primed enhancer

Pioneer TF

Downstream TF

H3K4me1

- H3К9ас

- H3K27ac

Transcription factor binding site (TFBS)

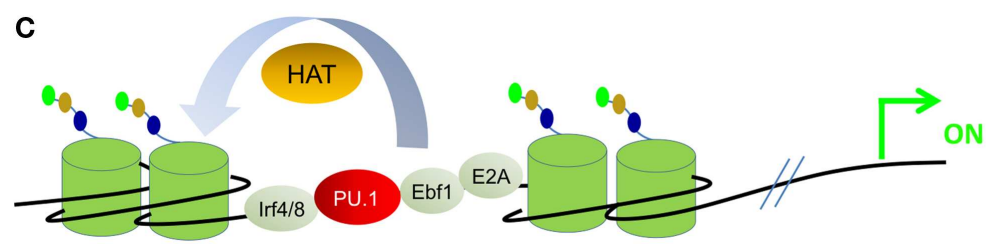

Active enhancer

FIGURE 4 | Simplified scheme of stepwise enhancer activation based on the pioneering model. A pioneer TF is exemplified by the ETS factor PU.1; the transcription start site (TSS) is indicated by a red or green arrow and the enhancer element is schematized by four nucleosomes. For simplicity, the nucleosomes covering the rest of the DNA including the promoter region are not indicated. (A) The pioneer TF recognizes and binds its cognate site in condensed chromatin.
(B) Recruitment of histone methyltransferases (HMTs) and chromatin remodeling complexes $(\mathrm{CRC})$ which prime the enhancer for subsequent activation. At this step, the enhancer now harbors H3K4me1 mark but still lacks acetylation marks. (C) Subsequent collaborative binding of downstream TFs accompanied by histone acetyl transferases (HATs) that catalyze histone acetylation, leading to enhancer activation and gene transcription.

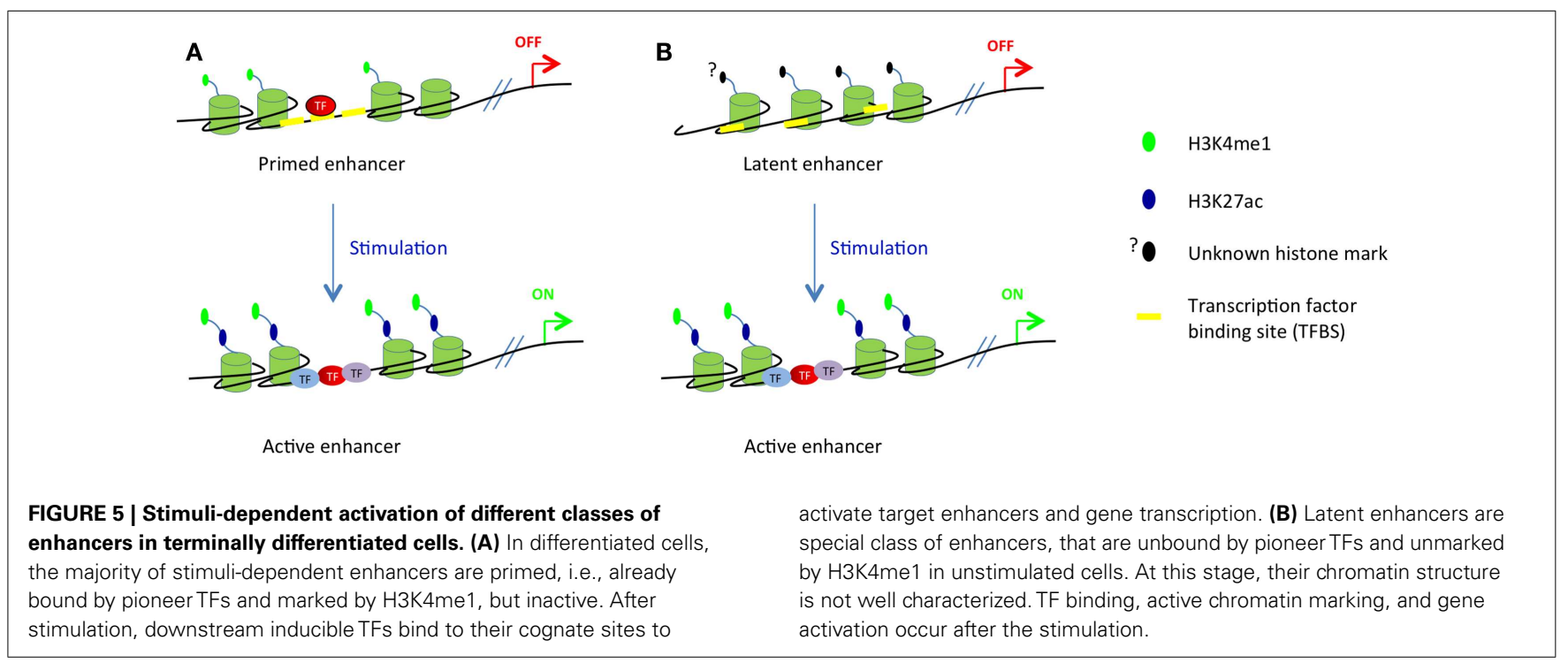

enhancers in macrophages. These cis-REs have been called "latent enhancers" and are not bound by TFs and also lack H3K4mel and acetylation marks under basal or uninduced conditions. However, they acquire all these features in response to stimulation (90) (see Figure 5). These data suggest that the priming may not be absolutely required for all enhancer elements; however, it cannot 
be excluded that upon the stimulation the priming occurs before the activation of target enhancers.

\section{UNDERSTANDING THE ORDER OF EVENTS}

In an effort to investigate how the enhancer repertoire is established and maintained during myeloid and B cell development, Mercer et al. have generated long-term cultures of hematopoietic progenitors by enforcing the expression of the E-protein antagonist Id2, which inhibits E2A activity by preventing its binding to DNA. These progenitors, called Id2-HPC, can be differentiated in vitro into myeloid and B cell lineages by switching off Id2 expression, therefore effectively restoring E2A activity. Using this system, H3K4mel mark was mapped in Id2-HPC cells as well as in myeloid and $\mathrm{B}$ cells generated in vitro from these artificial precursors. Interestingly, it was found that a substantial fraction of the lymphoid and myeloid enhancers were pre-marked by $\mathrm{H} 3 \mathrm{~K} 4 \mathrm{me} 1$ (i.e., primed) already in MPPs. Thus, multilineage priming of enhancer elements in hematopoietic progenitors precedes commitment to the lymphoid and myeloid cell lineages (85). Motif analysis showed that PU.1 and Runx motifs were over-represented in H3K4me1 enriched loci in Id2-HPC cells, while enhancers of genes activated after $\mathrm{B}$ cell differentiation were enriched in E2A and Ebf1 motifs, in addition to PU.1 motif (85). These finding clearly demonstrate a relationship between cell type-specific binding of TFs and the pattern of H3K4mel enhancer mark. They also indicate a potential role of PU.1 and Runx factors in priming enhancers in hematopoietic progenitors for subsequent downstream activation.

The correlation between PU.1 binding and presence of $\mathrm{H} 3 \mathrm{~K} 4 \mathrm{me} 1$ mark was also reported in other hematopoietic lineages, including B cells (30) and macrophages (89). However, it was unclear whether the $\mathrm{H} 3 \mathrm{~K} 4 \mathrm{me} 1$ modification serves as a beacon to recruit PU.1 and other TFs, or whether these TFs can initiate the deposition of $\mathrm{H} 3 \mathrm{~K} 4 \mathrm{mel}$ in hematopoietic progenitors. By expressing a tamoxifen-inducible PU.1/ER fusion protein in PU.1deficient myeloid progenitors (91), Heinz et al. demonstrated that PU.1 binding can induce $\mathrm{H} 3 \mathrm{~K} 4 \mathrm{mel}$ deposition at some loci; yet, many loci were found to lack H3K4mel despite the binding of PU.1, suggesting that additional factors may be required to write this mark (30). In addition, PU.1 was found to bind to loci that were already marked by $\mathrm{H} 3 \mathrm{~K} 4 \mathrm{me} 1$; in this case PU.1 was found to be able to initiate nucleosome remodeling (30).

An earlier study has shown that the intronic enhancer of the Pax5 gene is bound and regulated by PU.1, IRF4, IRF8, and NF-KB (55). Interestingly, the chromatin at this enhancer harbors active marks already in progenitors and is bound by PU.1 and IRF factors before Pax5 transcription takes place in committed pro-B cells (55). It was also shown that the concerted action of PU.1 and Runx1 primes the activation of both promoter and enhancer elements of the $c$-fms gene in myeloid cell $(92,93)$. All together, these data clearly indicate the pioneering and priming abilities of the master hematopoietic regulator PU.1. This is consistent with its expression during early hematopoietic cell differentiation from HSCs onward and its dynamic collaborative binding with various TFs.

E2A was also found to alter the $\mathrm{H} 3 \mathrm{~K} 4 \mathrm{mel}$ pattern at enhancer elements in B cell progenitors, however it is unclear whether E2A can directly induce de novo $\mathrm{H} 3 \mathrm{~K} 4$ mono-methylation or only modulate the positioning of nucleosomes already pre-marked by H3K4me1 via nucleosome remodeling mechanisms (24).

Other downstream TFs such as Ebf1 and Pax5 were also found to regulate chromatin structure at cis-REs. For example, Ebf1 plays a role in the demethylation of the $C d 79 a$ promoter in B cell progenitors (94). Ebf1 is also crucially required for the remodeling and activation of chromatin in the Pax5 promoter region (55). Pax5 regulates chromatin structure by recruiting chromatin-modifying and remodeling complexes to the Pax5 regulated loci (57). Interestingly, Pax5 fulfills both activation and repression functions; it induces active chromatin at promoters and enhancers of activated target genes, while eliminating active chromatin at the regulatory elements of repressed target genes. Pax 5 rapidly induces $\mathrm{H} 3 \mathrm{~K} 4$ methylation and $\mathrm{H} 3 \mathrm{~K} 9$ acetylation at enhancers and promoters of activated target genes. Pax 5 activation function involves direct interaction with the chromatin-remodeling SWI/SNF-like BAF complex, the histone acetyltransferase CBP, and the PTIP protein, which is known to recruit the MLL-containing H3K4 methyltransferase complex to chromatin (95). The repressing activity of Pax5 is mediated by its ability to recruit the NCoR1 co-repressor complex with its associated HDAC3 enzyme, which is likely responsible for histone deacetylation at some Pax5 repressed loci (57). Pax5 was also found to interact with members of the co-repressor Groucho family, thus leading to repression of target genes (96). An intriguing question is how TFs such as Ikaros and Pax5, having both activation and repression abilities, can distinguish which set of genes must be repressed or activated.

FoxO TFs were also described to have pioneering capacity [reviewed in Ref. (97)] and FoxO1 was found to be able to bind to its cognate sites in condensed chromatin. This binding stably perturbs core histone by de-condensing linker histone-compacted chromatin (98), possibly because the FoxO DBD shares structural similarities with the globular domain of the linker histones $\mathrm{H} 1$ and H5 (99, 100). Furthermore, the amino-terminal and carboxyterminal regions of FoxO1 mediate histone $\mathrm{H} 3$ and $\mathrm{H} 4$ binding (98). By functioning as pioneer factors, FoxO TFs might open condensed regions and allow the binding of other TFs.

Overall, these studies demonstrated that chromatin structure in hematopoietic progenitors and committed cells can act as a beacon for binding of some TFs. Conversely, TFs such as PU.1, E2A, Ebf1, and many others, can modulate chromatin features at cis-REs to create or enhance a chromatin environment favorable for the binding of additional TFs. The priming and activation of cis-REs requires the collaborative and/or cooperative action of several TFs. For example, in B cells, the pioneer TF PU.1 co-occupies enhancers with E2A, Ebf1, and Oct2, while in macrophages it binds together with AP-1 and C/EBP (30). However, the synergy between pioneer and downstream TFs is not simply hierarchical but also involves cross-regulatory interactions. For example, at certain loci, PU.1 binding in B cells depends on E2A and Ebf1 (30) in spite of the fact that these two factors were not clearly identified as pioneer TFs. What regulates whether PU.1 binds by itself or requires other factors is not known, but is likely to involve the precise binding site and/or the local chromatin structure. It is also not established whether the pioneer TFs identified so far are a special class of factors with unique properties, or whether most factors can 
act as pioneers in the right context. Thus, the term "pioneer TF" does not have an absolute meaning, but should rather be viewed as a useful descriptor for properties identified in specific cases. Indeed, a downstream TF can act as a pioneer for an upstream $\mathrm{TF}$, and vice versa, in a context- and locus-dependent manner. Therefore, many TFs involved in the priming of cis-RE can fall into the category of pioneer TFs. However, as mentioned above, it is often difficult to unambiguously monitor the precise chronological binding order of a set of TFs and corresponding epigenetic modifications under in vivo conditions. Thus, instead of using the term pioneer when the evidence is scarce, it may be better to rather speak about collaborative action of TFs at a given locus.

\section{CONCLUDING REMARKS}

In summary, the questions of who is on first, the chromatin or the TF, when, and why/how are still largely unanswered. In some physiological situations, specific chromatin features must precede and are required for TF binding, while in other situations the TF binding initiates a series of epigenetic events eventually required for the recruitment of downstream TFs. The extensive efforts that were made to investigate transcriptional and epigenetic regulation of B cells and other hematopoietic lineages identified several mechanisms of cross-regulation between TFs, chromatin modifiers, and the pre-existing chromatin landscape. The interactions between the actors cited above are very likely to be controlled by environmental, spatial, and temporal signals that remain to be defined. Also, many additional factors - TFs, chromatin modifiers, non-coding RNAs .... - remain to be tested for their potential role in the hematopoietic system or in B cells. However, achieving a deeper understanding of the mechanisms involved will require the ability to examine single cells in real-time to understand how the interplay between chromatin and TFs is orchestrated and unambiguously determine causal relationships. Also, the ability to genetically manipulate the system, not only at the level of the TFs or other trans-acting factors, but also of the cis-REs, e.g., by using the newly developed CRISPR/Cas9 (clustered regularly interspaced short palindromic repeats) system (101) will be invaluable to further our understanding.

\section{ACKNOWLEDGMENTS}

This work was supported by the Novartis Research Foundation and the Swiss National Science Foundation SystemsX Cell Plasticity grant. We thank Benjamin Herquel (Max Planck Institute, Freiburg), Antonius G. Rolink (Basel University DBM, Basel), Makoto Saito, and Roger Clerc for critical reading of the manuscript and valuable comments.

\section{REFERENCES}

1. Luger K, Mäder AW, Richmond RK, Sargent DF, Richmond TJ. Crystal structure of the nucleosome core particle at 2.8 A resolution. Nature (1997) 389(6648):251-60. doi:10.1038/38444

2. Kooistra SM, Helin K. Molecular mechanisms and potential functions of histone demethylases. Nat Rev Mol Cell Biol (2012) 13(5):297-311. doi:10.1038/ nrm3327

3. Lei H, Oh SP, Okano M, Jüttermann R, Goss KA, Jaenisch R, et al. De novo DNA cytosine methyltransferase activities in mouse embryonic stem cells. Development (1996) 122(10):3195-205.

4. Bird AP, Wolffe AP. Methylation-induced repression - belts, braces, and chromatin. Cell (1999) 99(5):451-4. doi:10.1016/S0092-8674(00)81532-9
5. Lister R, Pelizzola M, Dowen RH, Hawkins RD, Hon G, Tonti-Filippini J, et al. Human DNA methylomes at base resolution show widespread epigenomic differences. Nature (2009) 462(7271):315-22. doi:10.1038/nature08514

6. Yoder JA, Soman NS, Verdine GL, Bestor TH. DNA (cytosine-5)methyltransferases in mouse cells and tissues. Studies with a mechanism-based probe. J Mol Biol (1997) 270(3):385-95. doi:10.1006/jmbi.1997.1125

7. Okano M, Takebayashi S, Okumura K, Li E. Assignment of cytosine-5 DNA methyltransferases Dnmt3a and Dnmt3b to mouse chromosome bands 12A2-A3 and $2 \mathrm{H} 1$ by in situ hybridization. Cytogenet Cell Genet (1999) 86(3-4):333-4. doi:10.1159/000015331

8. Wu SC, Zhang Y. Active DNA demethylation: many roads lead to Rome. Nat Rev Mol Cell Biol (2010) 11(9):607-20. doi:10.1038/nrm2950

9. Ito S, D'Alessio AC, Taranova OV, Hong K, Sowers LC, Zhang Y. Role of Tet proteins in $5 \mathrm{mC}$ to $5 \mathrm{hmC}$ conversion, ES-cell self-renewal and inner cell mass specification. Nature (2010) 466(7310):1129-33. doi:10.1038/nature09303

10. Zhang P, Su L, Wang Z, Zhang S, Guan J, Chen Y, et al. The involvement of 5-hydroxymethylcytosine in active DNA demethylation in mice. Biol Reprod (2012) 86(4):104. doi:10.1095/biolreprod.111.096073

11. Mueller-Planitz F, Klinker H, Becker PB. Nucleosome sliding mechanisms: new twists in a looped history. Nat Struct Mol Biol (2013) 20(9):1026-32. doi: $10.1038 / \mathrm{nsmb} .2648$

12. Watanabe S, Peterson CL. The INO80 family of chromatin-remodeling enzymes: regulators of histone variant dynamics. Cold Spring Harb Symp Quant Biol (2010) 75:35-42. doi:10.1101/sqb.2010.75.063

13. Mercer TR, Dinger ME, Mattick JS. Long non-coding RNAs: insights into functions. Nat Rev Genet (2009) 10(3):155-9. doi:10.1038/nrg2521

14. Iwasaki H, Akashi K. Myeloid lineage commitment from the hematopoietic stem cell. Immunity (2007) 26(6):726-40. doi:10.1016/j.immuni.2007.06.004

15. Kondo M, Weissman IL, Akashi K. Identification of clonogenic common lymphoid progenitors in mouse bone marrow. Cell (1997) 91(5):661-72. doi:10.1016/S0092-8674(00)80453-5

16. Akashi K, Traver D, Miyamoto T, Weissman IL. A clonogenic common myeloid progenitor that gives rise to all myeloid lineages. Nature (2000) 404(6774):193-7. doi:10.1038/35004599

17. Adolfsson J, Borge OJ, Bryder D, Theilgaard-Mönch K, Astrand-Grundström I, Sitnicka E, et al. Upregulation of Flt3 expression within the bone marrow $\operatorname{Lin}(-) \operatorname{Sca} 1(+)$ c-kit $(+)$ stem cell compartment is accompanied by loss of selfrenewal capacity. Immunity (2001) 15(4):659-69. doi:10.1016/S1074-7613(01) 00220-5

18. Adolfsson J, Månsson R, Buza-Vidas N, Hultquist A, Liuba K, Jensen CT, et al. Identification of Flt3+ lympho-myeloid stem cells lacking erythromegakaryocytic potential a revised road map for adult blood lineage commitment. Cell (2005) 121(2):295-306. doi:10.1016/j.cell.2005.02.013

19. Igarashi H, Gregory SC, Yokota T, Sakaguchi N, Kincade PW. Transcription from the RAG1 locus marks the earliest lymphocyte progenitors in bone marrow. Immunity (2002) 17(2):117-30. doi:10.1016/S1074-7613(02) 00366-7

20. Inlay MA, Bhattacharya D, Sahoo D, Serwold T, Seita J, Karsunky H, et al. Ly6d marks the earliest stage of B-cell specification and identifies the branchpoint between B-cell and T-cell development. Genes Dev (2009) 23(20):2376-81. doi:10.1101/gad.1836009

21. Matthias P, Rolink AG. Transcriptional networks in developing and mature B cells. Nat Rev Immunol (2005) 5(6):497-508. doi:10.1038/nri1633

22. Hendriks RW, Middendorp S. The pre-BCR checkpoint as a cell-autonomous proliferation switch. Trends Immunol (2004) 25(5):249-56. doi:10.1016/j.it. 2004.02.011

23. Perlot T, Alt FW. Cis-regulatory elements and epigenetic changes control genomic rearrangements of the IgH locus. Adv Immunol (2008) 99:1-32. doi:10.1016/S0065-2776(08)00601-9

24. Lin YC, Jhunjhunwala S, Benner C, Heinz S, Welinder E, Mansson R, et al. A global network of transcription factors, involving E2A, EBF1 and Foxo1, that orchestrates B cell fate. Nat Immunol (2010) 11(7):635-43. doi:10.1038/ ni. 1891

25. Zhang Q, Iida R, Yokota T, Kincade PW. Early events in lymphopoiesis: an update. Curr Opin Hematol (2013) 20(4):265-72. doi:10.1097/MOH. 0b013e3283612628

26. Wang F, Tong Q. Transcription factor PU.1 is expressed in white adipose and inhibits adipocyte differentiation. Am J Physiol Cell Physiol (2008) 295(1):C213-20. doi:10.1152/ajpcell.00422.2007 
27. McKercher SR, Torbett BE, Anderson KL, Henkel GW, Vestal DJ, Baribault H, et al. Targeted disruption of the PU.1 gene results in multiple hematopoietic abnormalities. EMBO J (1996) 15(20):5647-58.

28. Iwasaki H, Somoza C, Shigematsu H, Duprez EA, Iwasaki-Arai J, Mizuno S, et al. Distinctive and indispensable roles of PU.1 in maintenance of hematopoietic stem cells and their differentiation. Blood (2005) 106(5):1590-600. doi:10. 1182/blood-2005-03-0860

29. Klemsz MJ, McKercher SR, Celada A, Van Beveren C, Maki RA. The macrophage and B cell-specific transcription factor PU.1 is related to the ets oncogene. Cell (1990) 61(1):113-24. doi:10.1016/0092-8674(90)90219-5

30. Heinz S, Benner C, Spann N, Bertolino E, Lin YC, Laslo P, et al. Simple combinations of lineage-determining transcription factors prime cis-regulatory elements required for macrophage and B cell identities. Mol Cell (2010) 38(4):576-89. doi:10.1016/j.molcel.2010.05.004

31. Back J, Allman D, Chan S, Kastner P. Visualizing PU.1 activity during hematopoiesis. Exp Hematol (2005) 33(4):395-402. doi:10.1016/j.exphem. 2004.12.010

32. DeKoter RP, Singh H. Regulation of B lymphocyte and macrophage development by graded expression of PU.1. Science (2000) 288(5470):1439-41. doi:10.1126/science.288.5470.1439

33. Georgopoulos K, Bigby M, Wang JH, Molnar A, Wu P, Winandy S, et al. The Ikaros gene is required for the development of all lymphoid lineages. Cell (1994) 79(1):143-56. doi:10.1016/0092-8674(94)90407-3

34. Yoshida T, Ng SY, Zuniga-Pflucker JC, Georgopoulos K. Early hematopoietic lineage restrictions directed by Ikaros. Nat Immunol (2006) 7(4):382-91. doi:10.1038/ni1314

35. Ng SY, Yoshida T, Zhang J, Georgopoulos K. Genome-wide lineage-specific transcriptional networks underscore Ikaros-dependent lymphoid priming in hematopoietic stem cells. Immunity (2009) 30(4):493-507. doi:10.1016/j. immuni.2009.01.014

36. Reynaud D, Demarco IA, Reddy KL, Schjerven H, Bertolino E, Chen Z, et al. Regulation of B cell fate commitment and immunoglobulin heavychain gene rearrangements by Ikaros. Nat Immunol (2008) 9(8):927-36. doi:10.1038/ni.1626

37. Heizmann B, Kastner P, Chan S. Ikaros is absolutely required for pre-B cell differentiation by attenuating IL-7 signals. J Exp Med (2013) 210(13):2823-32. doi:10.1084/jem.20131735

38. Sridharan R, Smale ST. Predominant interaction of both Ikaros and Helios with the NuRD complex in immature thymocytes. J Biol Chem (2007) 282(41):30227-38. doi:10.1074/jbc.M702541200

39. O’Neill DW, Schoetz SS, Lopez RA, Castle M, Rabinowitz L, Shor E, et al. An ikaros-containing chromatin-remodeling complex in adult-type erythroid cells. Mol Cell Biol (2000) 20(20):7572-82. doi:10.1128/MCB.20.20.7572-7582. 2000

40. Kim J, Sif S, Jones B, Jackson A, Koipally J, Heller E, et al. Ikaros DNA-binding proteins direct formation of chromatin remodeling complexes in lymphocytes. Immunity (1999) 10(3):345-55. doi:10.1016/S1074-7613(00)80034-5

41. Cobb BS, Morales-Alcelay S, Kleiger G, Brown KE, Fisher AG, Smale ST. Targeting of Ikaros to pericentromeric heterochromatin by direct DNA binding. Genes Dev (2000) 14(17):2146-60. doi:10.1101/gad.816400

42. Brown KE, Guest SS, Smale ST, Hahm K, Merkenschlager M, Fisher AG. Association of transcriptionally silent genes with Ikaros complexes at centromeric heterochromatin. Cell (1997) 91(6):845-54. doi:10.1016/S0092-8674(00)80472-9

43. Bain G, Maandag EC, Izon DJ, Amsen D, Kruisbeek AM, Weintraub BC, et al. E2A proteins are required for proper B cell development and initiation of immunoglobulin gene rearrangements. Cell (1994) 79(5):885-92. doi:10.1016/0092-8674(94)90077-9

44. Zhuang Y, Soriano P, Weintraub $H$. The helix-loop-helix gene E2A is required for B cell formation. Cell (1994) 79(5):875-84. doi:10.1016/0092-8674(94) 90076-0

45. Kee BL, Murre C. Induction of early B cell factor (EBF) and multiple B lineage genes by the basic helix-loop-helix transcription factor E12. J Exp Med (1998) 188(4):699-713. doi:10.1084/jem.188.4.699

46. Welinder E, Mansson R, Mercer EM, Bryder D, Sigvardsson M, Murre C. The transcription factors E2A and HEB act in concert to induce the expression of FOXO1 in the common lymphoid progenitor. Proc Natl Acad Sci U S A (2011) 108(42):17402-7. doi:10.1073/pnas.1111766108
47. Daburon V, Mella S, Plouhinec JL, Mazan S, Crozatier M, Vincent A. The metazoan history of the COE transcription factors. Selection of a variant HLH motif by mandatory inclusion of a duplicated exon in vertebrates. BMC Evol Biol (2008) 8:131. doi:10.1186/1471-2148-8-131

48. Hagman J, Gutch MJ, Lin H, Grosschedl R. EBF contains a novel zinc coordination motif and multiple dimerization and transcriptional activation domains. EMBO J (1995) 14(12):2907-16.

49. Zandi S, Ahsberg J, Tsapogas P, Stjernberg J, Qian H, Sigvardsson M. Single-cell analysis of early B-lymphocyte development suggests independent regulation of lineage specification and commitment in vivo. Proc Natl Acad Sci U S A (2012) 109(39):15871-6. doi:10.1073/pnas.1210144109

50. Lin H, Grosschedl R. Failure of B-cell differentiation in mice lacking the transcription factor EBF. Nature (1995) 376(6537):263-7. doi:10.1038/376263a0

51. Zandi S, Mansson R, Tsapogas P, Zetterblad J, Bryder D, Sigvardsson M. EBF1 is essential for B-lineage priming and establishment of a transcription factor network in common lymphoid progenitors. J Immunol (2008) 181(5): 3364-72.

52. Treiber T, Mandel EM, Pott S, Györy I, Firner S, Liu ET, et al. Early B cell factor 1 regulates $B$ cell gene networks by activation, repression, and transcriptionindependent poising of chromatin. Immunity (2010) 32(5):714-25. doi:10. 1016/j.immuni.2010.04.013

53. Roessler S, Györy I, Imhof S, Spivakov M, Williams RR, Busslinger M, et al. Distinct promoters mediate the regulation of Ebfl gene expression by interleukin-7 and Pax5. Mol Cell Biol (2007) 27(2):579-94. doi:10.1128/MCB.01192-06

54. Thal MA, Carvalho TL, He T, Kim HG, Gao H, Hagman J, et al. Ebfl-mediated down-regulation of Id 2 and Id 3 is essential for specification of the $\mathrm{B}$ cell lineage. Proc Natl Acad Sci U S A (2009) 106(2):552-7. doi:10.1073/pnas.0802550106

55. Decker T, Pasca di Magliano M, McManus S, Sun Q, Bonifer C, Tagoh H, et al. Stepwise activation of enhancer and promoter regions of the B cell commitment gene Pax5 in early lymphopoiesis. Immunity (2009) 30(4):508-20. doi:10.1016/j.immuni.2009.01.012

56. Urbánek P, Wang ZQ, Fetka I, Wagner EF, Busslinger M. Complete block of early B cell differentiation and altered patterning of the posterior midbrain in mice lacking Pax5/BSAP. Cell (1994) 79(5):901-12. doi:10.1016/00928674(94)90079-5

57. McManus S, Ebert A, Salvagiotto G, Medvedovic J, Sun Q, Tamir I, et al. The transcription factor Pax 5 regulates its target genes by recruiting chromatinmodifying proteins in committed B cells. EMBO J (2011) 30(12):2388-404. doi:10.1038/emboj.2011.140

58. Cobaleda C, Jochum W, Busslinger M. Conversion of mature B cells into $\mathrm{T}$ cells by dedifferentiation to uncommitted progenitors. Nature (2007) 449(7161):473-7. doi:10.1038/nature06159

59. Dengler HS, Baracho GV, Omori SA, Bruckner S, Arden KC, Castrillon DH, et al. Distinct functions for the transcription factor Foxol at various stages of $\mathrm{B}$ cell differentiation. Nat Immunol (2008) 9(12):1388-98. doi:10.1038/ni.1667

60. Amin RH, Schlissel MS. Foxol directly regulates the transcription of recombination-activating genes during $\mathrm{B}$ cell development. Nat Immunol (2008) 9(6):613-22. doi:10.1038/ni.1612

61. Fahl SP, Crittenden RB, Allman D, Bender TP. c-Myb is required for pro-B cell differentiation. J Immunol (2009) 183(9):5582-92. doi:10.4049/jimmunol. 0901187

62. Seo W, Ikawa T, Kawamoto H, Taniuchi I. Runx1-Cbfbeta facilitates early B lymphocyte development by regulating expression of Ebfl. J Exp Med (2012) 209(7):1255-62. doi:10.1084/jem.20112745

63. Huang G, Zhang P, Hirai H, Elf S, Yan X, Chen Z, et al. PU.1 is a major downstream target of AML1 (RUNX1) in adult mouse hematopoiesis. Nat Genet (2008) 40(1):51-60. doi:10.1038/ng0208-255a

64. Mak KS, Funnell AP, Pearson RC, Crossley M. PU.1 and haematopoietic cell fate: dosage matters. Int J Cell Biol (2011) 2011:808524. doi:10.1155/2011/808524

65. Aloia L, Di Stefano B, Di Croce L. Polycomb complexes in stem cells and embryonic development. Development (2013) 140(12):2525-34. doi:10.1242/ dev.091553

66. Su IH, Basavaraj A, Krutchinsky AN, Hobert O, Ullrich A, Chait BT, et al. Ezh2 controls B cell development through histone H3 methylation and Igh rearrangement. Nat Immunol (2003) 4(2):124-31. doi:10.1038/ni876

67. Aldiri I, Vetter ML. PRC2 during vertebrate organogenesis: a complex in transition. Dev Biol (2012) 367(2):91-9. doi:10.1016/j.ydbio.2012.04.030 
68. van der Lugt NM, Domen J, Linders K, van Roon M, Robanus-Maandag E, te Riele $\mathrm{H}$, et al. Posterior transformation, neurological abnormalities, and severe hematopoietic defects in mice with a targeted deletion of the bmi-1 protooncogene. Genes Dev (1994) 8(7):757-69. doi:10.1101/gad.8.7.757

69. Akasaka T, Tsuji K, Kawahira H, Kanno M, Harigaya K, Hu L, et al. The role of mel-18, a mammalian Polycomb group gene, during IL-7-dependent proliferation of lymphocyte precursors. Immunity (1997) 7(1):135-46. doi:10.1016/ S1074-7613(00)80516-6

70. Coré N, Bel S, Gaunt SJ, Aurrand-Lions M, Pearce J, Fisher A, et al. Altered cellular proliferation and mesoderm patterning in Polycomb-M33-deficient mice. Development (1997) 124(3):721-9.

71. Park IK, Qian D, Kiel M, Becker MW, Pihalja M, Weissman IL, et al. Bmi-1 is required for maintenance of adult self-renewing haematopoietic stem cells. Nature (2003) 423(6937):302-5. doi:10.1038/nature01587

72. Oguro H, Iwama A, Morita Y, Kamijo T, van Lohuizen M, Nakauchi H. Differential impact of Ink4a and Arf on hematopoietic stem cells and their bone marrow microenvironment in Bmil-deficient mice. J Exp Med (2006) 203(10):2247-53. doi:10.1084/jem.20052477

73. Oguro H, Yuan J, Ichikawa H, Ikawa T, Yamazaki S, Kawamoto H, et al. Poised lineage specification in multipotential hematopoietic stem and progenitor cells by the polycomb protein Bmil. Cell Stem Cell (2010) 6(3):279-86. doi:10.1016/j.stem.2010.01.005

74. Calés C, Román-Trufero M, Pavón L, Serrano I, Melgar T, Endoh M, et al. Inactivation of the polycomb group protein Ring1B unveils an antiproliferative role in hematopoietic cell expansion and cooperation with tumorigenesis associated with Ink4a deletion. Mol Cell Biol (2008) 28(3):1018-28. doi:10.1128/MCB.01136-07

75. Mochizuki-Kashio M, Mishima Y, Miyagi S, Negishi M, Saraya A, Konuma T, et al. Dependency on the polycomb gene Ezh2 distinguishes fetal from adult hematopoietic stem cells. Blood (2011) 118(25):6553-61. doi:10.1182/blood2011-03-340554

76. Yamaguchi T, Cubizolles F, Zhang Y, Reichert N, Kohler H, Seiser C, et al. Histone deacetylases 1 and 2 act in concert to promote the G1-to-S progression. Genes Dev (2010) 24(5):455-69. doi:10.1101/gad.552310

77. Trowbridge JJ, Snow JW, Kim J, Orkin SH. DNA methyltransferase 1 is essential for and uniquely regulates hematopoietic stem and progenitor cells. Cell Stem Cell (2009) 5(4):442-9. doi:10.1016/j.stem.2009.08.016

78. Bröske AM, Vockentanz L, Kharazi S, Huska MR, Mancini E, Scheller M, et al. DNA methylation protects hematopoietic stem cell multipotency from myeloerythroid restriction. Nat Genet (2009) 41(11):1207-15. doi:10.1038/ng.463

79. Challen GA, Sun D, Jeong M, Luo M, Jelinek J, Berg JS, et al. Dnmt3a is essential for hematopoietic stem cell differentiation. Nat Genet (2012) 44(1):23-31. doi:10.1038/ng.1009

80. Nakase H, Takahama Y, Akamatsu Y. Effect of CpG methylation on RAG1/RAG2 reactivity: implications of direct and indirect mechanisms for controlling V(D)J cleavage. EMBO Rep (2003) 4(8):774-80. doi:10.1038/sj.embor.embor904

81. Selimyan R, Gerstein RM, Ivanova I, Precht P, Subrahmanyam R, Perlot T, et al. Localized DNA demethylation at recombination intermediates during immunoglobulin heavy chain gene assembly. PLoS Biol (2013) 11(1):e1001475. doi:10.1371/journal.pbio.1001475

82. Cherry SR, Beard C, Jaenisch R, Baltimore D. V(D)J recombination is not activated by demethylation of the kappa locus. Proc Natl Acad Sci U S A (2000) 97(15):8467-72. doi:10.1073/pnas.150218497

83. Gray KS, Forrest JC, Speck SH. The de novo methyltransferases DNMT3a and DNMT3b target the murine gammaherpesvirus immediate-early gene 50 promoter during establishment of latency. J Virol (2010) 84(10):4946-59. doi:10.1128/JVI.00060-10

84. Rickert RC, Roes J, Rajewsky K. B lymphocyte-specific, Cre-mediated mutagenesis in mice. Nucleic Acids Res (1997) 25(6):1317-8. doi:10.1093/nar/25.6.1317

85. Mercer EM, Lin YC, Benner C, Jhunjhunwala S, Dutkowski J, Flores M, et al. Multilineage priming of enhancer repertoires precedes commitment to the $\mathrm{B}$ and myeloid cell lineages in hematopoietic progenitors. Immunity (2011) 35(3):413-25. doi:10.1016/j.immuni.2011.06.013

86. Zaret KS, Carroll JS. Pioneer transcription factors: establishing competence for gene expression. Genes Dev (2011) 25(21):2227-41. doi:10.1101/gad. 176826.111
87. Gualdi R, Bossard P, Zheng M, Hamada Y, Coleman JR, Zaret KS. Hepatic specification of the gut endoderm in vitro: cell signaling and transcriptional control. Genes Dev (1996) 10(13):1670-82. doi:10.1101/gad.10.13.1670

88. Bossard P, Zaret KS. GATA transcription factors as potentiators of gut endoderm differentiation. Development (1998) 125(24):4909-17.

89. Ghisletti S, Barozzi I, Mietton F, Polletti S, De Santa F, Venturini E, et al. Identification and characterization of enhancers controlling the inflammatory gene expression program in macrophages. Immunity (2010) 32(3):317-28. doi:10.1016/j.immuni.2010.02.008

90. Ostuni R, Piccolo V, Barozzi I, Polletti S, Termanini A, Bonifacio S, et al. Latent enhancers activated by stimulation in differentiated cells. Cell (2013) 152(1-2):157-71. doi:10.1016/j.cell.2012.12.018

91. Walsh JC, DeKoter RP, Lee HJ, Smith ED, Lancki DW, Gurish MF, et al. Cooperative and antagonistic interplay between PU.1 and GATA-2 in the specification of myeloid cell fates. Immunity (2002) 17(5):665-76. doi:10.1016/S10747613(02)00452-1

92. Krysinska H, Hoogenkamp M, Ingram R, Wilson N, Tagoh H, Laslo P, et al. A two-step, PU.1-dependent mechanism for developmentally regulated chromatin remodeling and transcription of the c-fms gene. Mol Cell Biol (2007) 27(3):878-87. doi:10.1128/MCB.01915-06

93. Hoogenkamp M, Lichtinger M, Krysinska H, Lancrin C, Clarke D, Williamson A, et al. Early chromatin unfolding by RUNX1: a molecular explanation for differential requirements during specification versus maintenance of the hematopoietic gene expression program. Blood (2009) 114(2):299-309. doi:10.1182/blood-2008-11-191890

94. Maier H, Ostraat R, Gao H, Fields S, Shinton SA, Medina KL, et al. Early B cell factor cooperates with Runxl and mediates epigenetic changes associated with mb-1 transcription. Nat Immunol (2004) 5(10):1069-77. doi:10.1038/ni1119

95. Cho YW, Hong T, Hong S, Guo H, Yu H, Kim D, et al. PTIP associates with MLL3- and MLL4-containing histone H3 lysine 4 methyltransferase complex. J Biol Chem (2007) 282(28):20395-406. doi:10.1074/jbc.M701574200

96. Eberhard D, Jiménez G, Heavey B, Busslinger M. Transcriptional repression by Pax5 (BSAP) through interaction with corepressors of the Groucho family. EMBO J (2000) 19(10):2292-303. doi:10.1093/emboj/19.10.2292

97. Lalmansingh AS, Karmakar S, Jin Y, Nagaich AK. Multiple modes of chromatin remodeling by Forkhead box proteins. Biochim Biophys Acta (2012) 1819(7):707-15. doi:10.1016/j.bbagrm.2012.02.018

98. Hatta M, Cirillo LA. Chromatin opening and stable perturbation of core histone:DNA contacts by FoxO1. J Biol Chem (2007) 282(49):35583-93. doi:10.1074/jbc.M704735200

99. Clark KL, Halay ED, Lai E, Burley SK. Co-crystal structure of the HNF3/fork head DNA-recognition motif resembles histone H5. Nature (1993) 364(6436):412-20. doi:10.1038/364412a0

100. Ramakrishnan V, Finch JT, Graziano V, Lee PL, Sweet RM. Crystal structure of globular domain of histone $\mathrm{H} 5$ and its implications for nucleosome binding. Nature (1993) 362(6417):219-23. doi:10.1038/362219a0

101. Ran FA, Hsu PD, Wright J, Agarwala V, Scott DA, Zhang F. Genome engineering using the CRISPR-Cas9 system. Nat Protoc (2013) 8(11):2281-308. doi:10.1038/nprot.2013.143

Conflict of Interest Statement: The authors declare that the research was conducted in the absence of any commercial or financial relationships that could be construed as a potential conflict of interest.

Received: 24 January 2014; accepted: 25 March 2014; published online: 11 April 2014. Citation: Choukrallah MA and Matthias P (2014) The interplay between chromatin and transcription factor networks during B cell development: who pulls the trigger first? Front. Immunol. 5:156. doi: 10.3389/fimmu.2014.00156

This article was submitted to B Cell Biology, a section of the journal Frontiers in Immunology.

Copyright (C) 2014 Choukrallah and Matthias. This is an open-access article distributed under the terms of the Creative Commons Attribution License (CC BY). The use, distribution or reproduction in other forums is permitted, provided the original author(s) or licensor are credited and that the original publication in this journal is cited, in accordance with accepted academic practice. No use, distribution or reproduction is permitted which does not comply with these terms. 